If features of an acute severe attack are present recognise, assess, and manage the patient as outlined above and call the medical registrar or senior house officer to admit the patient. If the patient is unconscious or confused call the anaesthetist at the same time and arrange admission to the intensive care unit; ensure uninterrupted administration of high flow oxygen; and do not attempt intubation until the most expert available doctor (ideally an anaesthetist) is present.

If no features of an acute severe attack are present measure the peak expiratory flow and proceed as summarised in the figure. If the rate is $<40 \%$ of the predicted value or of the patient's best result treat the patient as for a severe attack. In all other patients give inhaled or nebulised $\beta_{2}$ agonist (see above for doses), and 30 minutes later measure the peak expiratory flow again (see box).

Before discharge determine why the patient attended the accident and emergency department. Such patients usually need extra care in their follow up. Ideally, contact the patient's general practitioner by telephone as soon as possible during surgery hours.

\section{Management of catastrophic sudden severe (brittle) asthma}

In patients with catastrophic sudden severe (brittle) asthma an attack of asthma becomes severe within minutes or a few hours, with little instability of asthma in the preceding days. Such patients are rare but are at great risk of sudden death. They are best handled by a management plan that is mutually agreed on by the patient, the general practitioner, and the consultant.

Patients should be constantly reviewed by a chest physician and carry a Medic-Alert bracelet or equivalent. They must also carry a $\beta_{2}$ agonist and prednisolone at all times and have duplicate supplies of drugs for emergencies to be kept in their handbag, car glove compartment, office, etc. Provision of a resuscitation box and oxygen cylinder to be kept in the patient's home should be considered.

As soon as an attack starts the patient's management plan might be:

(1) Call for help.

(2) Inhale a $\beta_{2}$ agonist at a high dose (for example, 2050 puffs, or nebulised salbutamol $5 \mathrm{mg}$, or terbutaline $10 \mathrm{mg}$ ).

If this management has been shown to be ineffective on previous occasions a syringe preloaded with adrenaline (Min-I-Jet, $0.5 \mathrm{mg}$ ) for subcutaneous injection may be helpful. The patient or relative, or both, must be shown how to use the syringe under supervision (using isotonic saline for practice). The shelf life is limited to six months. No similar $\beta_{2}$ agonist is commercially available.

(3) Swallow prednisolone $30-60 \mathrm{mg}$.

(4) Go to the nearest hospital as previously agreed with the general practitioner.

If such a patient is seen during an attack his or her history may suggest direct admission to the intensive care unit.

Participants in the development of the guidelines were-Dr D Costain, Dr B D W Harrison, Professor S T Holgate, Dr A P Hopkins, Dr M R Partridge (members of the organising committee); Professor P J Barnes, and Drs R A L Brewis, C E Bucknall, H R Gribbin, D J Lane, E Neville (who prepared the initial draft statements); and Dr S P Allison, Dr A H Barnett, Professor T J H Clark and Drs C K Connolly, G K Crompton, J Donaldson, C C Evans, A D Ferguson, J A R Friend, S R Hilton, W F Holmes, K Jones, S Kenwright, $M$ W McNicol, R L Page, C F A Pantin, M G Pearson, M Rudolf, A Smith, J E Stark, G O Thomas, Professor M E Turner-Warwick, and Dr C Waine.

1 British Thoracic Society, Research Unit of the Royal College of Physicians of London, King's Fund Centre, National Asthma Campaign. Guidelines for management of asthma in adults: I-chronic persistent asthma. Br Med J management of ast

(Accepted 3 August 1990)

\title{
Screening children from overseas for infections: Is it justified?
}

\author{
Neela Shabde, Tony Waterston
}

\section{Abstract}

Objectives-To investigate current practice of screening children from abroad for infections after coming to the United Kingdom, and to make recommendations for future practice.

Design-A review of literature and a questionnaire sent to all health authorities and boards in the United Kingdom.

Setting-All health authorities and boards in the United Kingdom.

Subjects -167 Health authorities or boards that completed questionnaires (response rate $80 \%$ ), 59 of which used a screening programme.

Main outcome measure-Response to questionnaire on policies for screening children for infections on their return from overseas.

Results -12 Of the 59 authorities screened all children and one screened only those from the West Indian subcontinent. 13 Authorities excluded children from school while awaiting results; 58 screened for tuberculosis and four for diphtheria.

Conclusions - There is a wide variation in screening policies around the country with no national consensus. Screening for diphtheria, typhoid, and salmonellosis is hard to justify and is probably not effective. Screening for tuberculosis, however, is supported by many authorities, is widely practised, and probably is effective. There is a strong case for rationalisation of screening.

\section{Introduction}

One of us was introduced dramatically to the "immigrant medical" system shortly after appointment to a community paediatrician post. An angry father telephoned to ask why his daughter, aged 7 , had to be excluded from school for a week on the family's return to Britain from Gibraltar, where he had served in the armed forces for two years. He had been told that his daughter had to have a throat swab, stool culture, and Heaf test and await the result before starting school and that this was the standard procedure. He thought the exclusion was unnecessary as the standard of medical care in Gibraltar was exemplary and his daughter was fit.

Local policy was that all children entering the country after more than two months in southern Europe, Africa, or Asia had to undergo routine screening for diphtheria, typhoid, salmonellosis, and tuberculosis. This policy was justified on the grounds that diphtheria and typhoid carriers had been detected and were a risk to the health of the public. 
We thought that such a policy required scientific validation and set out to find out, firstly, what the policy is in other parts of Britain; secondly, whether screening is necessary and effective; and, finally, what a rational policy would be.

There is no national policy on the performance of routine stool cultures or throat swabs in children who have returned from tropical countries (Department of Health, personal communication, 1988). In view of the national variation in screening policy for visual and hearing defects, ${ }^{12}$ we thought it would be helpful to carry out a survey of screening policies of health authorities throughout Britain.

TABLE I-Screening policies of 59 health authorities or boards

\begin{tabular}{lc}
\hline Children screened & $\begin{array}{c}\text { No of health authorities } \\
\text { or boards }\end{array}$ \\
\hline From Asia, Africa, central and south America & 31 \\
All & 12 \\
From outside European Commission & 4 \\
From beyond Great Britain, Ireland, and all & 2 \\
those re-entering after six months & 7 \\
$\begin{array}{l}\text { Those referred from port health and immigration } \\
\text { authorities }\end{array}$ & 1 \\
From West Indian subcontinent & 1 \\
Those absent from school or country for over & 1 \\
three months &
\end{tabular}

TABLE II - Type of screening done by 59 health authorities or boards

\begin{tabular}{lc}
\hline Type of screening & $\begin{array}{c}\text { No of health authorities } \\
\text { or boards }\end{array}$ \\
\hline For tuberculosis & 58 \\
For diphtheria & 4 \\
Diphtheria vaccine offered to children & 1 \\
$\quad$ under 10 years & 17 \\
Stool culture and microscopy & 1 \\
Stool microscopy & (for Vietnamese only) \\
\hline
\end{tabular}

TABLE III - Numbers of subjects screened and problems arising from 27 health authorities or boards that kept records. Figures are numbers of children unless otherwise stated

\begin{tabular}{|c|c|c|}
\hline Health authority or board & $\begin{array}{l}\text { No screened } \\
(1988-9)\end{array}$ & Problems arising \\
\hline South Bedfordshire & 277 Families & $\left\{\begin{array}{l}\text { Open tuberculosis }(4)^{\star} \\
\text { Prophylaxis }(6)\end{array}\right.$ \\
\hline Sandwell & 280 & \\
\hline East Leeds & 225 & Bacterial or parasitic infection (49) \\
\hline North Hertfordshire & 5 & \\
\hline South Derbyshire & 140 & Unspecified (24) \\
\hline Walsall & 71 & Information not available \\
\hline Dewsbury & 591 & Unspecified (27) \\
\hline West Birmingham & 700 & Various \\
\hline \multicolumn{3}{|l|}{ Harrogate } \\
\hline Bradford & 356 & $\begin{array}{l}\text { Unspecified (53) } \\
\text { Helminth infection (170) }\end{array}$ \\
\hline Pontefract & I Family & \\
\hline Bury & 7 & Unspecified \\
\hline Leicestershire & 555 & Needed BCG (122) \\
\hline Calderdale & 144 & $\left\{\begin{array}{l}\text { Campylobacter infection }(8) \\
\text { Shigella infection (2) } \\
\text { Ova, cysts, and occasionally worms (22) }\end{array}\right.$ \\
\hline Darlington & 12 Families & Tuberculosis on arrival ( 1 adult) \\
\hline Wolverhampton & 63 & \\
\hline Blackburn & 251 & $\left\{\begin{array}{l}\text { Negative Heaf tests, given BCG }(42) \\
\text { Positive Heaf tests }(206)(21 \text { referred to contact clinic) }\end{array}\right.$ \\
\hline Greater Glasgow & 265 & \\
\hline Aylesbury & 5 & \\
\hline South Glamorgan & 13 & $\left\{\begin{array}{l}\text { Positive Heaf tests }(7) \\
\text { Required further investigation (1) }\end{array}\right.$ \\
\hline Hounslow & 418 & Very few \\
\hline East Cumbria & 1 & \\
\hline Central Manchester & 68 & \\
\hline Ayrshire & 33 & Positive Heaf tests (4) \\
\hline Scunthorpe & 44 & Some needed BCG \\
\hline Southport & 9 (over 2 years) & \\
\hline Coventry & 47 & $\begin{array}{l}\text { Entamoeba (1) } \\
\text { Giardia lamblia, Trichuris trichiura, Ascaris lumbricoides, } \\
\quad \text { Giardia lamblia }\end{array}$ \\
\hline
\end{tabular}

*Authority did not specify whether problem was in adult or child.

\section{Methods}

We sent questionnaires to all 209 health authorities and boards in England, Wales, and Scotland asking about their policies on screening children entering Britain from abroad. The response rate was $80 \%$ (167 replies). Fifty nine of the health authorities that replied used a screening programme. Of the 108 authorities that did not have a screening programme, 22 screened for tuberculosis alone followed by a BCG if necessary. One authority's policy was not to respond to questionnaires because of shortage of staff.

\section{Results}

Table I summarises the screening policies of the 59 health authorities with a screening programme. Policies were variable - for example, 12 screened all children regardless of origin and one screened only those from the West Indian subcontinent. There seemed to be no justification for the variation in policy. Table II shows the type of screening carried out. Most authorities (58) screened for tuberculosis, though a few screened for diphtheria and infective diarrhoea.

Of the health authorities that replied, 13 excluded children from school until screening was completed; these authorities have an appreciable ethnic minority -immigrant population. One health authority stated that it was planning to alter its practice on the advice of the former Inner London Education Authority that it is illegal to attach any conditions to admission to school.

There was no uniformity on where responsibility for screening lay or who collected the specimens.

Table III summarises the data collected from 27 authorities that kept records on numbers screened and the results. Tuberculosis was the only important disease detected.

\section{Discussion}

\section{IS SCREENING NECESSARY AND EFFECTIVE?}

The reasons for screening children may be justified on two grounds - firstly, to benefit the children themselves and, secondly, to protect other children. Screening for the child's benefit is desirable and is the traditional purpose of the school health service. A child coming from outside the district without documentation of screening tests should be assessed for short stature, congenital heart disease, undescended testes in a boy, and hearing and visual defects. A child coming from a tropical country might be screened for asymptomatic infestations such as bilharzia and hookworm. This kind of testing is good practice and would be a normal part of surveillance. A second purpose of screening is to detect conditions that could affect other children. This is the main reason for many of the tests done on children starting school after a period abroad. These conditions are the major communicable diseases, in particular, diphtheria, infective diarrhoea, and tuberculosis.

We were unable to locate any data from published reports or from local sources to show whether screening is effective. The consensus appears to be that screening for tuberculosis is effective (though it has been suggested that it would be better to do the screening in the country of origin), ${ }^{3}$ but there is considerable doubt on the effectiveness of screening for diphtheria and intestinal infections.

In Newcastle 82 children were referred to the tuberculosis contact clinic for further investigation after "immigrant medicals" over the past two years (1987-8). Of these, 72 were given BCG, nine were given prophylactic isoniazid, and nine were already immune. None were treated. No new cases of tuber- 
culosis were therefore detected by this form of screening.

In the case of the other tests, a carrier of nontoxigenic diphtheria and a carrier of typhoid were detected by screening during the past five years in Newcastle. Detailed information was not, however, kept on the origin and outcome of these infections. It is thought not to be worth while taking throat swabs from asymptomatic children who have been in a tropical country for eight weeks or more, and routine screening may not even avert rare cases of toxigenic diphtheria (N Noah, personal communication, 1988).

Varying periods of between eight weeks and six months abroad appear to be chosen as conveying a higher risk of contracting one of the target infectious diseases. Alternatively, tests are sometimes applied only to children coming to Britain for the first time. Why should a particular period be chosen? The influencing factors seem to be $(a)$ the usual length of package holidays (under four weeks) and $(b)$ the time needed to contract tuberculosis. Typhoid and diphtheria could be contracted on a very short holiday, but at least several weeks of exposure would be required for tuberculosis. An arbitrary decision must therefore be taken on the length of the period of risk. We suggest eight weeks because it is hallowed by usage and there seems to be no strong rationale for change.

The possible adverse effects of screening children on their return from overseas are that it stigmatises children from ethnic minorities as unhealthy or unhygienic and keeps them away from school at an important period of settling in.

\section{CONCLUSIONS}

Our review of screening for infections in children entering Britain from overseas shows that there is a wide variation in screening policies around the country with no national consensus. Screening for tuberculosis is, however, supported by many authorities, is widely practised, and is probably effective, being mainly of value to the child screened. On the other hand, screening for diphtheria, typhoid, and salmonella is hard to justify and is probably not effective. There is therefore a strong case for rationalising screening, concentrating on the detection of tuberculosis. We should also ensure that advice on prevention of disease is readily available to families before they travel abroad.

We have initiated the following procedure in Newcastle, which we recommend as a national policy. This guidance applies to children entering the education system after spending over eight weeks in a tropical country (Asia, the Far East, Africa, and south America).

(1) The school nurse will interview the family before the child starts school and review the child's health followed by a Heaf test and BCG if this is negative. Some children, however, will have already started school and the family will therefore be interviewed as soon as possible.

(2) The child will normally start school as soon as the interview has been done, provided no symptoms of serious infection have been found - for example, severe sore throat, fever, chronic cough, loss of weight.

(3) The child will be referred to the school doctor at the nurse's discretion or if immunisation is required. If required information will be given on how to register with a general practitioner.

(4) A record will be kept of each interview.

We thank Professor Norman Noah for his comments.

Stewart-Brown SL, Haslum M. Screening of vision in school: could we do better by doing less? Br Med 7 1988;297:1111-3.

2 Stewart-Brown SL, Haslum M. Screening for hearing loss in childhood: a study national practice. BrMed f 1987;294:1386-8.

3 Kilpatrick GS. Global tuberculosis. In: Hobson W, ed. Theory and practice of public health. 4th ed. London: Oxford University Press, 1975:340-54.

(Accepted 16 fuly 1990)

\title{
Lesson of the Week
}

\section{Invasive aspergillosis in immunosuppressed patients: potential hazard of hospital building work}

\author{
A G Dewhurst, M J Cooper, S M Khan, A P Pallett, J R E Dathan
}

Aspergillus fumigatus is an important pathogen acquired from contaminated air. Invasive aspergillosis is increasingly recognised in immunocompromised patients in haematology, oncology, or transplant units. The disease is often difficult to diagnose ${ }^{23}$ and carries a high mortality if untreated, ${ }^{1+}$ and treatment itself may be hazardous. The problem may not be widely appreciated by clinicians managing patients receiving immunosuppressive treatment for other diseases. Furthermore, there is a well recognised association between demolition and construction work and outbreaks of invasive aspergillosis. ${ }^{4-x}$

We report on three patients who developed invasive aspergillosis while receiving immunosuppressive therapy for systemic vasculitides at the same time as demolition work was occurring on the hospital site. All three patients died. In two of them invasive aspergillosis was the cause of death and in the third it was a contributory factor.

\section{Case reports}

CASE 1

A 73 year old woman developed breathlessness and was found to have pulmonary oedema, which improved with diuretics. She had a history of hypertension and ischaemic heart disease. Investigations showed the following concentrations: urea $27 \mathrm{mmol} / \mathrm{l}$ (normal 3-6.5), creatinine $584 \mu \mathrm{mol} / \mathrm{l}(60-125)$, and haemoglobin $138 \mathrm{~g} / \mathrm{l}$. The erythrocyte sedimentation rate was $55 \mathrm{~mm}$ in the first hour. A midstream specimen of urine contained no casts or red blood cells, and a 24 hour urine collection contained $0.92 \mathrm{~g}$ of protein $(<0 \cdot 3 \mathrm{~g})$. An intravenous urogram showed an absent left kidney with a right kidney of normal size which concentrated poorly. Serum complement and immunoglobulin concentrations were normal and blood cultures were sterile. Acute glomerulonephritis was diagnosed. The patient declined renal biopsy. She improved with conservative management and was discharged home two weeks later with a serum creatinine concentration of $191 \mu \mathrm{mol} / \mathrm{l}$.

She presented again five months later with increasing breathlessness. A chest $x$ ray film showed bilateral pleural effusions with patchy basal consolidation. Serum creatinine concentration was $294 \mu \mathrm{mol} / \mathrm{l}$, haemoglobin concentration $93 \mathrm{~g} / \mathrm{l}$, and erythrocyte sedimentation rate $105 \mathrm{~mm}$ in the first hour. A pleural 